\title{
EMG PSD Measures in Orthodontic Appliances
}

\author{
Şükrü Okkesim ${ }^{1}$, Tancan Uysal2 ${ }^{2}$, Aslı Baysal ${ }^{3}$ and Sadık Kara ${ }^{1}$ \\ ${ }^{1}$ Fatih University, Institute of Biomedical Engineering, İstanbul \\ 2İzmir Katip Çelebi University, Faculty of Dentistry, Izmir \\ ${ }^{3}$ Kocaeli University, Faculty of Dentistry, Kocaeli
}

Turkey

\section{Introduction}

The human body consists of different systems which include the nervous system, the cardiovascular system, the musculoskeletal system, etc. Each system performs some kind of vital task and carries on many physiological processes. For example, the primary functions of the musculoskeletal system can be summarized as generating forces, producing motion, moving substance within the body, providing stabilization, and generating heat. Physiological processes are multifaceted fact and most of them manifest themselves as signals that reflect their nature and activities. These types of signals may be hormonal, physical or electrical. The general name of the electrical signals taken from the related organ or physiologic process with invasive or non-invasive methods is called Biomedical Signals. This signal is normally a function of time and is definable in terms of its amplitude, frequency and phase (Rangayyan, 2002).

The electromyography (EMG) signal is a biomedical signal that detects the electrical potential generated by muscle cells when these cells contract, and also when the cells are at rest. Three types of muscle tissue can be identified. One of them is the skeletal muscle, and the others are the smooth muscle and the cardiac muscle. The EMG is applied to the study of skeletal muscle (Reaz et al., 2006).

Skeletal muscles are comprised by nearly parallel cells and the muscle fibers which constitute the contractile structural units. Muscle fibers are activated by the central nervous system through electrical signals transmitted by motoneurons. A single motoneuron together with the muscle fibers that it contacts is called a motor unit which is the smallest functional subdivision of the neuromuscular system (Moritani, et al. 2004) The central nervous system controls the activation of motor units to optimize the interaction between our body and the surrounding environment. When the motor units are activated by the central nervous system, they produce an action potential trains of the active motor units add together to generate the interference EMG signal.

Surface and needle electrodes have been used to detect EMG of muscles. Surface electrodes have been widely used to investigate neuromuscular functions because of their several advantages, for example, it is noninvasive, easy to adhere to the skin and to detect the total activities of the muscle and it was called Surface EMG (SEMG). Bu the real advantage of this technique is that it is more beneficial in studies, in which simultaneous movement of many muscles is examined in vast muscle groups. On the other hand, surface electrodes have disadvantages as well. Due to the broad area for receiving signals on respective muscle 
bundle, signals received by surface electrodes may stem from proximal muscle groups. This situation leaves questions about the accuracy of records. Although a great deal of effort is spent to determine and characterize the effect of such artefacts, a technique of analysis that completely allays questions has not been developed yet (Cobbold, 1974).

SEMG has advantages and disadvantages; they are used widely for several issues. SEMG signals are used widely for diagnosis and to assess the treatment of some neuropathic, myopathic and neuromuscular junction diseases in the hospital and in research about biomechanics, sport medicine and rehabilitation ...etc.

Orthodontics is the branch of science dealing with teeth, jaw and face structure in terms of treatment of abnormalities/irregularities.

In orthodontics treatment performed with two different 'point of views'. One of them is the jaw orthopaedics in which the malposition of the jaws related to face or related to each other is corrected with special appliances. The other is called orthodontics and related with the correction of teeth. Generally patients are treated simultaneously with orthodontic and orthopaedic approaches.

Malocclusion is the general name of the orthodontic abnormalities arising from misalignment of teeth and incorrect relation between the upper and lower jaw and divided into Class I, II and III. Class II malocclusion is one of the most common orthodontic problems, and it is reported to constitute nearly one-third of all orthodontic disorders (Kraus, 1956 ; and Kleissen et al., 1998).

Class II malocclusions can be skeletal or dental. In skeletal Class II malocclusions the maxilla and the maxillary arch may be positioned anteriorly related to cranial base, the mandibula and the mandibular arch may be positioned posteriorly related to cranial base or the combination of these two factors. Treatment of Class II malocclusions achieved with orthopaedic and orthodontic approaches (Riedel, 1952; McNamara, 1981; Renfroe, 1948; Blair, 1954). Dental Class II malocclusions are arising from the increase in the inclination of upper incisor, crowding etc. As dental Class II malocclusion does not include skeletal problems, orthodontic corrections are sufficient for this type of malocclusions. The variability of Class II malocclusions cause to arise a lot of treatment options. Treatment options include non-oral or oral appliances, arch expansion mechanics and treatment with dental extractions (Proffit et al., 1998).

Non-oral appliances are one of the oldest treatment methods that are used widespread. The most common widespread non-oral appliance is headgear. As headgear can be used for steering or curbing the growth of upper jaw to the forward and downward (overbite), it can also be used for activating teeth in distal direction. Therefore, it can be said for this appliance that it has both orthopaedic and orthodontic effects. In addition to such advantages, the use of this appliance being difficult and the length of its service life diminish its chance for success. Additionally, the sight formed because of the appliance being placed upon the face and skull causes aesthetic considerations and for this reason, adaptation problems with patients come into existence. Non-oral appliances entail cooperation of patients given that they both pay attention to service life of apparatus and ignore the abovementioned disadvantages. Oral appliances were designed that do not entail cooperation with patients, increase his/her quality of life to be able to prevent this situation called patient cooperation (McNamara \& Brudon, 2001; Hunter, 1967; Rogers, 1984).

The aim of treatment using oral appliances is to change the bone structure of the face and direction of development. Although oral appliances are designed to treat each type of malocclusion, they are most successful in the Class II malocclusion. Oral appliances can be divided three groups, called active, passive and functional (Basciftci et al., 2003). 
Limiting maxillary growth, the possible development in mandibular position and its growth and the change in teeth position and muscle structure are the expected effects of functional appliances (Clark, 2002). In addition to that the use of functional appliance leads to alterations in tissues around teeth and mouth of patients, it was observed in conducted studies that it can restrict the growth of mid-face to forward, bring about a change in the location of the glenoid fossa and also changes that increase bone construction and destruction in the neuromuscular anatomy and function (Jena et al., 2006 ; Harvold, 1985 ; Pancherz, 1982 ; Birkeback et al., 1984)

Functional appliances are designed for the available pace of adaptive skeletal growth in people keeping the mandible forward (McNamara, 1981). Additionally, it produces a reciprocal effect between the maxillary and mandibular structures and the appliance itself by stimulating muscular and circulatory systems.

It is stated in the Orthodontic literature that Herbst and Twin-Block appliances are the most frequently used functional appliances. Both appliances are effective in correction of class II malocclusions (Lund \& Sandler, 1998). In particular, the studies conducted in the last 10 years proved the effectiveness of Twin-Block appliance (Mills C \& McCulloch, 1998).

Albeit the Twin-Block appliance is placed within the mouth, it is an appliance having unrestraint in fulfilling normal functions of mouth, at the same time providing higher level freedom in anterior and lateral movements in comparison with other appliances and that is used the whole day (Clark, 1982; Clark, 1988).

The Twin-Block appliance consisting of bite blocks and acrylic artificial palate pertaining to mandibular and maxillary bones was presented by Clark in 1970's. This appliance consists of sub and upper parts arriving to the contact point (junction) at a 70-degree angle. These parts provide stability in closing the jaw (Clark, 1982; Clark, 1988) (Figure 1.)

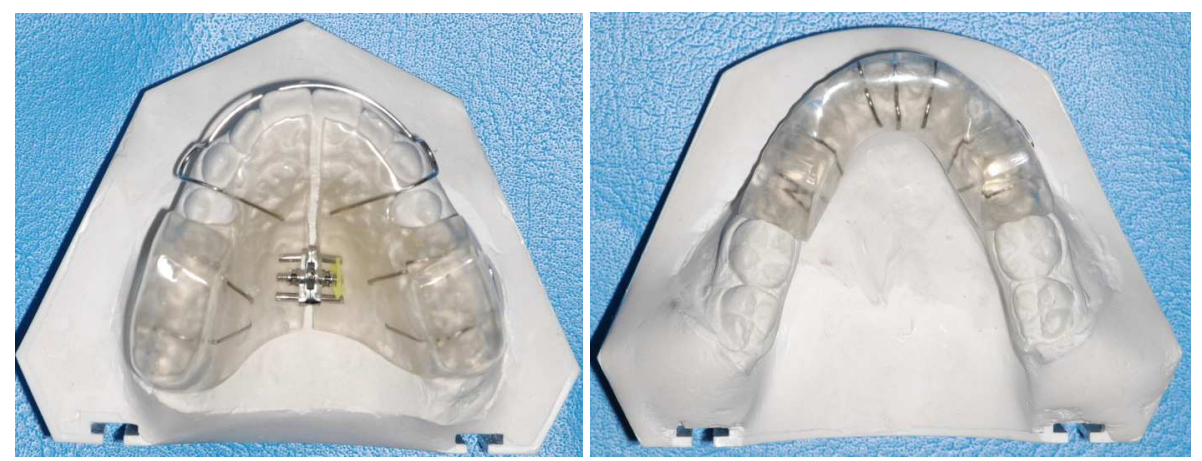

Fig. 1. Sub and Upper Parts of the Twin-block Appliance.

This appliance was preferred in our study owing to these advantages provided by the TwinBlock appliance and they being used incrementally by dentists in the last 10 years. Orthodontists are obliged to inform their patients about the different appliances, duration of treatment and about the possible changes in this period. For this aim, image of the skull is obtained; using X-ray or ultrasound techniques, thereafter jaw and teeth abnormalities are diagnosed. The name of this method is cephalometry (Figure 2). However, advantages of the appliances compared to one another and which one is more useful for one kind of abnormalities is determined by only experiences of Orthodontists. 


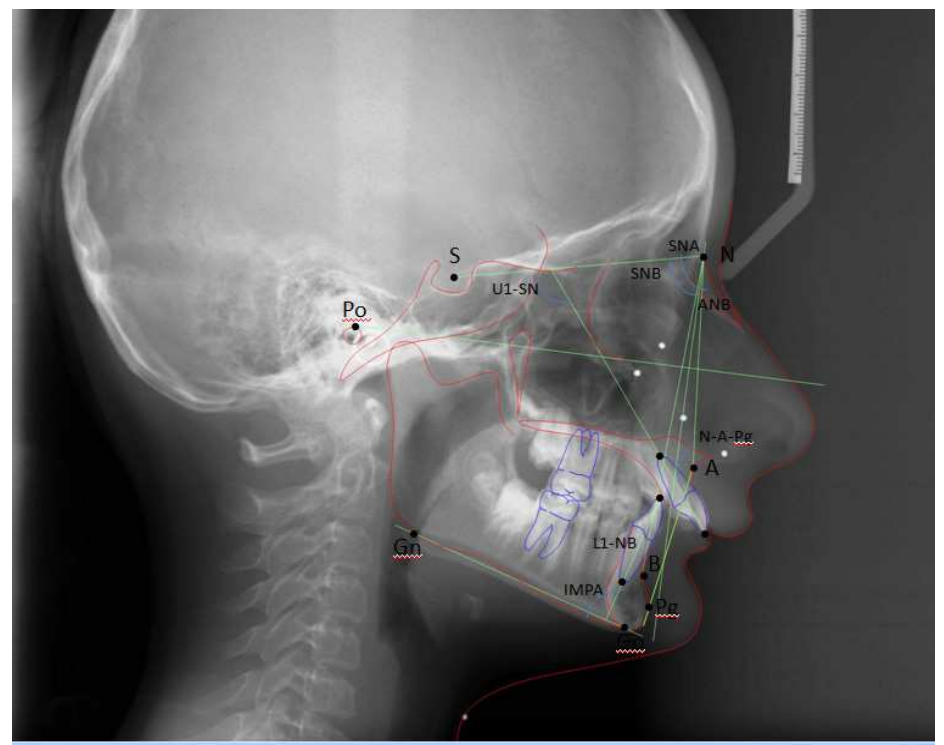

Fig. 2. Cephalometry image and some points of measurement.

Results taken from cephalometric records proved that functional appliances used in the treatment of malocclusion allay the abnormality in the mouth by affecting the alignment of teeth and bone tissue (Graber, 1985). Having said that, many different approaches/hypotheses are proposed regarding how neuromuscular periphery of teeth and bone tissue adapt to the change developed after treatment and the interaction between functional appliance and neuromuscular structure. Protraction in sizes of muscle fibers after the start of use of appliances (Woodside, 1983), the change in muscle dimensions caused by rotation of bone structure and hypertrophy of muscle structure can be given as examples to these hypotheses (McNamara, 1973).

One of the most important reasons for this difference between hypotheses is that there is no reliable and precise reference line in cephalometric image analysis used in evaluating treatment results. This situation complicates the assessment of significant changes occurring in skeletal and tooth structure (Pancherz, 1984). Additionally, it is impossible to obtain information about cephalometric image analysis and neuromuscular adaptation process and be informed about the changing muscle and bone structure during treatment process.

The principle objective of this study is to be able to put forth the interaction between functional appliances and neuromuscular structure with more scientific findings. If treatment can be assessed by quantitative data, as orthodontists can inform their patients about the issues such as treatment process, possible success ratio and etc. and also they can clearly decide which appliance is more suitable for patient as well. The electrophysiological signal that allows noninvasive assessment for changes in muscle structure is EMG. For these reasons, EMG studies continue with an increasing interest to find quantitative solutions such as problems and to measure of muscular activity changes because of the appliances.

In order to achieve this aim, we use EMG signals and their appropriate features to measure and evaluate Twin-Blok related muscular activity changes in Anterior Temporal and Masseter muscles in children with Class II malocclusion. 
For this aim power spectral density (PSD) graphics were obtained using EMG and maximum power spectral density value (Max PSD) and area of the PSD graphics (Area PSD) were calculated and changes between before treatment and at the end of the six months were analyzed statistically. Furthermore, Cephalometric images were taken before treatment and at the end of six months and changes in the position with respect to base of the skull were measured to make a comparison.

\subsection{Advancement of functional appliances}

Albeit first trials were worthy of note, treatment with functional appliances progressed by Roux's studies pertaining to natural forces and functional stimulation. Subsequently, Rogers advocated functional treatment and associated facial muscles with the development and form of the masticatory system (Woodside, 1983).

In 1920's, Andreasen set out to use the appliance that he developed in Class II malocclusions. Emil Herbst introduced the Herbst appliance in 1905 and published findings in 1935. In 1970's, Pancerz's studies on the Herbst appliance and findings that he attained led to this appliance used by dentists more frequently. The advantages of the Herbst appliance are that it is fixed on teeth and treatment period is short. Many studies have been conducted on short and long term effects of the appliance (Pancherz, 1991; Mcnamara \& Fränkel, 2002; Pancherz \& Fackel, 1990). Following the introduction of the Herbst appliance, different disadvantages caused the development of various appliances to be used in treatment of Class II malocclusion (Vogt, 2003; Awbrey, 1999). disadvantages experienced in treatment by the Herbst appliance can be summarized as that it is not hygienic, it is rigid and therefore, it restricts lateral movements of the mandible quite a lot (Pancherz, 1985). Another functional appliance similar to this appliance is the Jasper Jumper appliance. This appliance brings about food accumulation inside as well due to its structure. The Bite Fixer appliance was developed to be able to overcome such disadvantages. The Bite Fixer appliance is more flexible and does not allow food accumulation thanks to polyurethane tube situating inside but it was observed to cause open bite in the posterior area in some cases (open bite: occlusion not being able to materialize between the mandible and maxilla in the respective region) (Awbrey, 1999).

Inspired by a case in which the left gonial area disappeared, Bimler saw that mandible movements deliver force to the maxilla and the maxillary arch broadened. The Bimler appliance appeared in the literature in 1949 after many modifications since the day this study was conducted to the present day (Rogers, 1984).

Kesling presented the positioner appliance in 1944. In 1950, Balters began to modify the appliance that Andreasen developed and ensured via modifications he made that talking with this appliance is achieved in a more comfortable fashion (Pancherz et.al, 1989). In 1957, taking into account the structure of skeletal-muscular system that leads to structural and functional changes, Frankel designed his appliance (Proffit \& Fields, 2000). Different than other functional appliances, the appliance he named as Kinetor and defined by Stockfish incorporates elastic tubes between two plaques and is considered to optimize oral muscle pressures.

\section{Materials and methods}

\subsection{Measurement of surface EMG signals}

EMG recordings were extracted from patients fitting Class II malocclusion criteria below, from the right anterior temporal and right masseter muscles of 15 patients whose ages 
varied 8 and 13. Treatments of patients, who fit the criteria, were launched via the TwinBlock appliance in the Department of Orthodontics of the Faculty of Dentistry in Erciyes University [Figure 3]. None of the participants underwent orthodontic treatment before. Before each recording session, the procedure was explained in detail to the patient and their parents to allay anxiety.
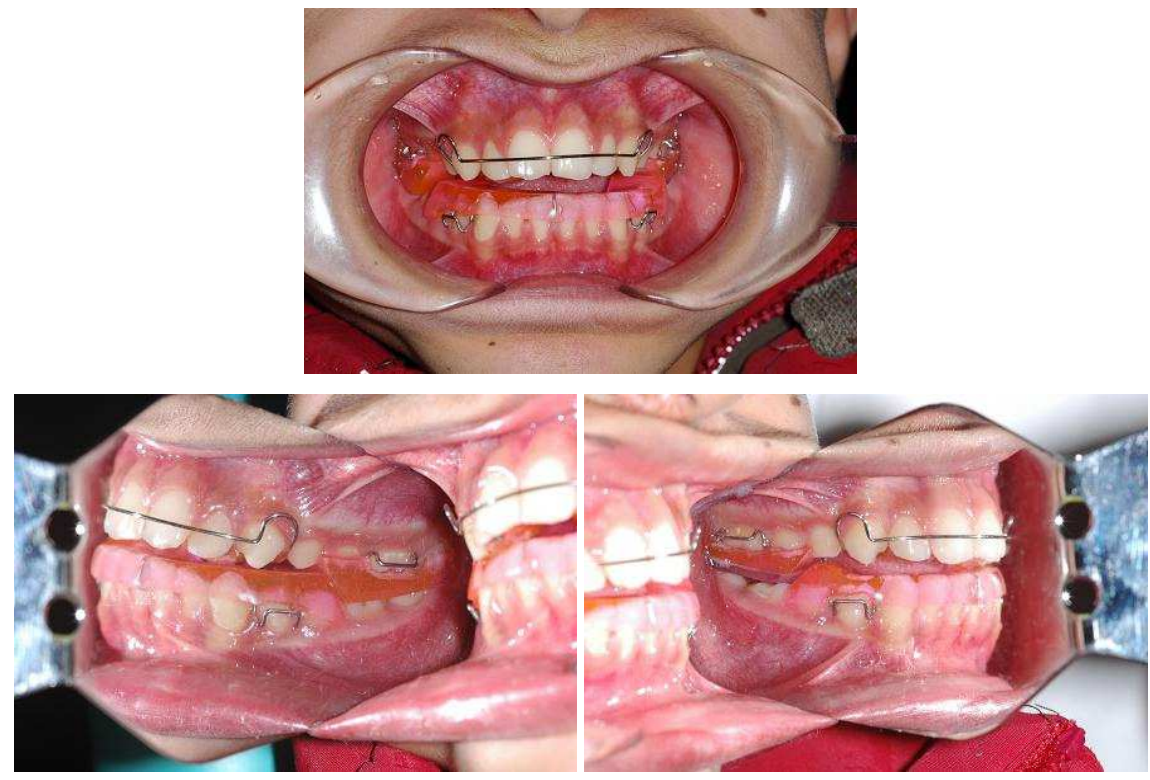

Fig. 3. Twin-block placement in situ.

Class II malocclusion criteria applied in our study:

Inclusion criteria

- $\quad$ Skeletal Class II relationship $\left(\mathrm{ANB}>4^{\circ}\right)$

- Mandibular retrognathy $\left(\mathrm{SNB}<78^{\circ}\right)$

- Overjet $\geq 5 \mathrm{~mm}$

- Minimal crowding in dental arches ( $\leq 4 \mathrm{~mm})$

- $\quad$ Bilateral Class II molar and canine relation (at least $3.5 \mathrm{~mm}$ )

Exclusion criteria

- Previous history of orthodontic treatment

- Congenitally missing or extracted permanent tooth (except third molars)

- Posterior crossbites or severe maxillary transverse deficiency

- Severe facial asymmetry determined by clinical or radiographical examination

- Systemic diseases that may affect the orthodontic treatment results

Patients were asked to wash their faces with soap for face grease not to affect recordings and then recorded regions were wiped with alcohol and dried. Patients were suggested to sit up straight and look across while recordings were being kept. Electrodes were attached on the muscle bundles, which were found by palpating, by surgical plastic strips (adhesive washers) that do not irritate the skin. Filling silver-surfaced, bipolar electrodes with $4 \mathrm{~mm}$. radius with electrode gel, they were sticked in a way that inter-electrode distance will be 2 
$\mathrm{cm}$. The common ground electrodes were adhered onto the forehead of the subject and the active electrodes were placed on the right anterior temporal and right masseter muscles as shown in Figure 4.

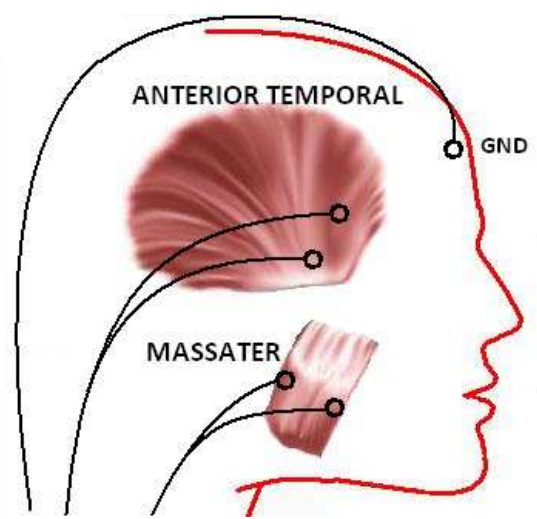

Fig. 4. Placement of surface electrodes on the anterior temporal and masseter muscles.

An important factor that affects recording quality is whether the spot where electrodes adhered and the region where muscle bundle is situated is the same. When the muscle, whose EMG recordings are sought to be taken, possesses a small area, electrodes also perceive signals coming from adjacent muscles and appear as noisy within EMG signals pertaining to the interested muscle bundle (Duchêne \& Gouble 1993). Such noises can be avoided by selecting the electrode surface proportional with inter-electrode distance. The selection of appropriate electrode surface size and inter-electrode distance to be kept small diminishes the affect that will stem from the distance between electrode and source and shifts EMG bandwidth to high frequency region. Electrode diameter for bipolar recording should be as big as that can perceive muscle activity in acceptable amounts and at the same time as small as that does not pick activities of other muscles. Inter-electrode distance is described as the distance between the centres of conductive surfaces of electrodes. Interelectrode distance recommended for bipolar recording is $20 \mathrm{~mm}$ (Pozzo, 2004).

Temporal and masseter muscles are muscles taking a part in the mandibular protrusion and EMG recording was extracted from these muscles considering that they may be effective in re-positioning of the mandible during treatment, ensure the mandibular growth and their adaptations may have an impact on treatment results. Mouth activity, in which these muscles play the most active role, is the jaw clenching. Therefore, recordings were taken during clenching activity. The movement was previously practiced by copying the observer.

The signals were recorded in two periods: before the treatment ( 0 month) and at the end of 6 months [Figure 5]. At each session, EMG recordings were made during the appliances is not in situ.

The MP150 biomedical data acquisition unit (Biopac Systems, Goleta, CA, USA) was used for recording signals. All of the signals were sampled at $5000 \mathrm{~Hz}$ and digitized (A/D converted) at a resolution of 12 bits per sample by the MP150 unit.

The EMG100C amplifier module of the MP150 unit was used to amplify and filter with the following settings: $500 \mathrm{~Hz}$ Low-Pass (LP) filter, $1.0 \mathrm{~Hz}$ High-Pass (HP) filter, and 2000 gain. 

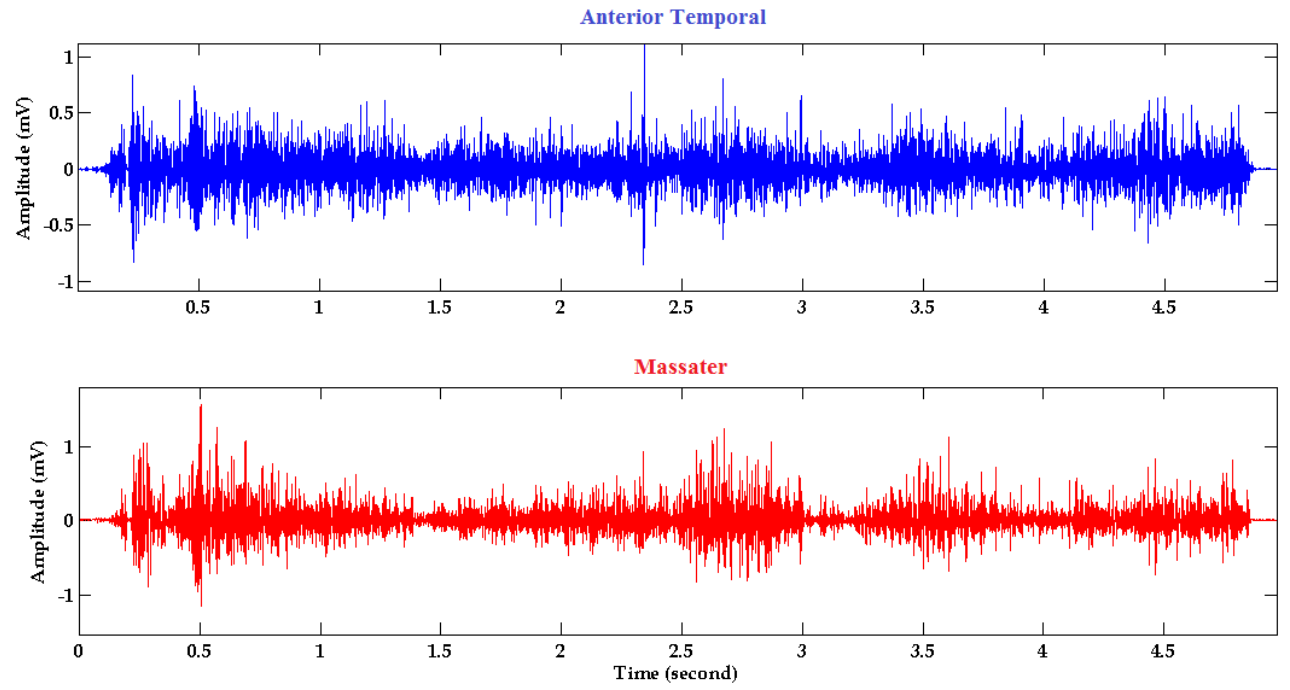

Fig. 5. Raw EMG Signals.

\subsection{Analysis of surface EMG signals}

There are two usual methods that have been used for the processing of EMG signals: frequency and time domain signal processing method. Some of the time domain signals processing methods are integration, linear envelope, and root mean square (RMS). However, these are are commonly not suitable, since obtained results depend on the selection of threshold [9].

The most powerful and generally used method for signal analysis in frequency domain had been the Fourier Transform (FT). FT is a method that assumes any signal is stationary. However, EMG signals are non-stationary (Panagiotacopulos, 1998)

Hence, the Fourier Transform cannot present satisfactory frequency resolution. In some respects, the Short Time Fourier Transform (STFT) is not perfectly suitable for processing of EMG signals. The main weakness inherent in the STFT is that trade off is inevitable between temporal and spectral resolution (Kim, 1989; Farina, 2004). If one uses a longer sliding time window to obtain higher spectral resolution, the underlying non-stationary will be smeared out, resulting in lower temporal resolution. Conversely, using a shorter window to achieve better temporal resolution will give lower spectral resolution. Because of these signal processing of the EMG signals were achieved using autoregressive (AR) model which is appropriate for non stationary signals and not having windowing problem (Kay, 1981). AR method is a parametric signal analysis method and first, model parameters of the available signal are estimated for such spectrum projection and then, the power spectral density value is calculated from these projection values (Kay, 1988). AR method is one of the most commonly used parametric methods owing to the fact that projection of AR parameters can be carried out easily with the resolution of linear equations. Signal that is modelled in AR method is causal.

The analysis conducted to demonstrate the distribution of power, which any physical signal that is carried to the frequency axis comprises, over frequency field is called as spectral 
analysis. In this way, graphs exhibiting the power density in frequency axis are denominated as the power spectral density (PSD) graph (Figure 6.).

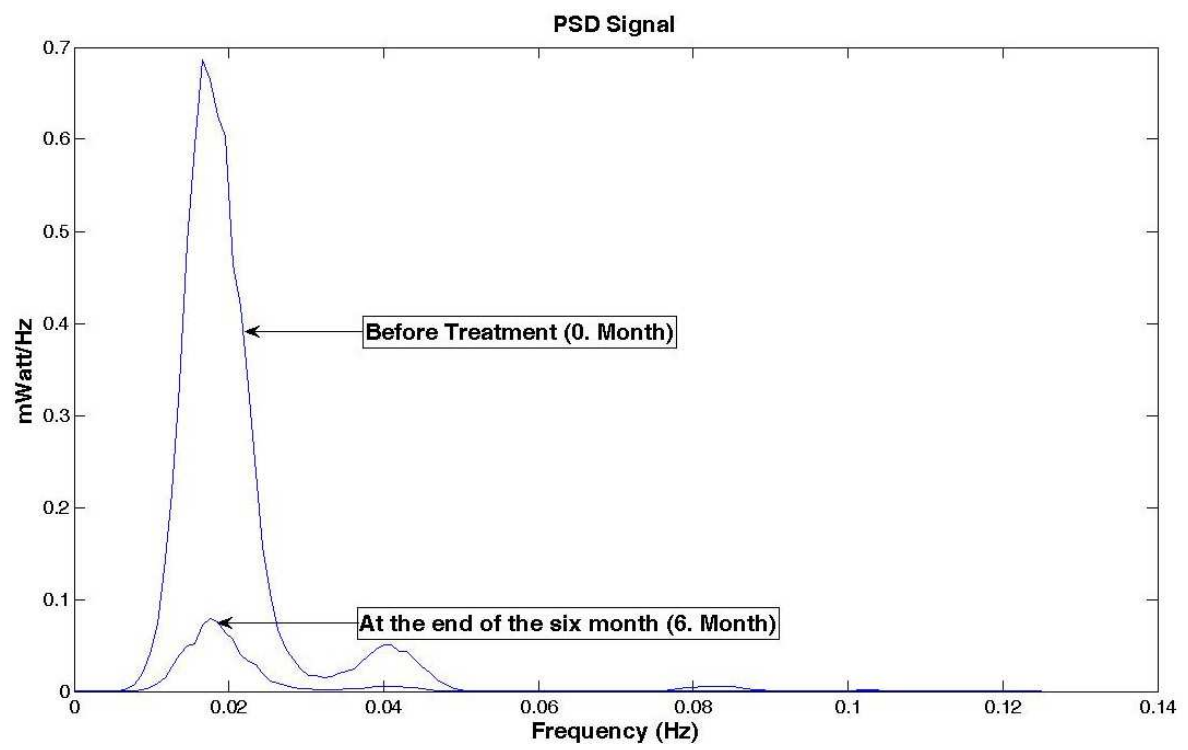

Fig. 6. The comparative display of PSD graphs calculated from EMG signals received at the end of the first and 6. Months.

EMG signal analysis that will be performed by addressing the power spectral density displaying the distribution of signal's energy capability in the frequency spectrum provides information about the neuromuscular conditions of motor units taking part during the activity (Okeson, 1998). The PSD values of EMG signals form as a result of the sum of spectral characteristics of action potentials of motor units. Consequently, it can be said that there is a characteristic power spectrum pertaining to every muscle (Blinowska, 1979). For these reasons, the PSD was used as a criterion in assessing the effect of appliance.

The maximum power spectral density value, which is a value of the PSD graph at its maximum point, varies by contraction density of motor units becoming active within that signal. The area below the PSD graph provides information about strain productivities of motor units carrying out contraction activity (Kwatny, 1970). Therefore maximum power spectral density value and area of the PSD graphics were calculated as a feature.

The AR model is a model revealing important informations in signal by using signal information in the past. It is employed widespread in biomedical signal processing because it responds well against noise. The dependence of past values to the future values is defined as autocorrelation function.

$$
\Gamma_{x x}(k)=\frac{1}{N} \sum_{n=1}^{N-k} x[n] x[n+k]
$$

where $\Gamma_{x x}[k]$ displays the signal's sample, which is shifted as much as $\mathrm{k}$, and its autocorrelation. The AR model; 


$$
x[n]=\sum_{i=1}^{p} a_{i} x[n-i]+\varepsilon[n]
$$

$x[n]$ shows the current value of time series, $\mathrm{a}_{1}, \ldots, \mathrm{a}_{\mathrm{p}}$ displays the AR model parameters, which are weighting coefficients, and $\mathrm{p}$ is the model degree showing the number of past values that will be used to estimate the current value and $\varepsilon[n]$ displays the approximate error with 1 scale.

By using the AR method, the power spectrum is attained as;

$$
P_{x x}^{A R}(f)=\frac{q_{e}^{2}}{\left|1-\sum_{i=1}^{p} a_{i} e^{-j 2 \pi f i}\right|}
$$

Where $q_{e}^{2}$, is the variance of $\varepsilon[n]$ error.

To calculate the AR parameters, whether numerical signal samples, whose spectral analysis will be directly conducted, are employed or autocorrelation function pertaining to these signal parameters is used. The Burg method was used for estimating the AR parameters (Marple, 1987).

One of the significant issues for employing the AR method is the selection of model degree. Many researchers studied on this problem and the Akaike Information Criteria (AIC) introduced by Akaike is used most commonly in the literature (Kaluzynski, 1989). The selection of AIC model degree is in the form of making the below statement minimum.

$$
\operatorname{AIC}(\mathrm{p})=\ln \sigma_{\mathrm{wp}}{ }^{2}+2 \mathrm{p} / \mathrm{N}
$$

Here, $\sigma_{\mathrm{wp}}{ }^{2}$ is the estimated variance of linear prediction error and $\mathrm{N}$ is the data length. $\sigma_{\mathrm{wp}}{ }^{2}$ decreases with the increase of the AR model degree and therefore, $\ln \sigma_{\mathrm{wp}}{ }^{2}$ decreases as well. That being said, $2 \mathrm{p} / \mathrm{N}$ increases too with the increase of $\mathrm{p}$. In this case, a minimum value should be designated for $\mathrm{p}$ (Kay, 1988; Kaluzynski, 1989). The $\mathrm{p}$ value calculated via the AIC criteria was obtained as 12 .

In order to take the fact that measurements were obtained from the same subjects into account, we used paired sample t-test for statistical comparison between 0 month and 6 months. A p-value of less than 0.05 was considered as statistically significant.

All of the data processing was carried out using in-house programs developed under MATLAB R2009b Software (MathWorks Inc., Natick MA, USA).

\section{Results and discussion}

The aim of present study is to use EMG signals and their appropriate features to measure and evaluate Twin-Blok related muscular activity changes in Anterior Temporal and Masseter muscles in children with Class II malocclusion.

For this aim power spectral density (PSD) graphics were obtained using EMG and Max PSD and Area PSD were calculated and changes between before treatment and at the end of the six months were analyzed statistically. Furthermore, Cephalometric images were taken before treatment and at the end of six months and changes in the position with respect to base of the skull were measured to make a comparison. 


\begin{tabular}{|c|c|c|c|c|}
\hline \multirow[t]{3}{*}{ Subject } & \multicolumn{4}{|c|}{ Anterior Temporal } \\
\hline & \multicolumn{2}{|c|}{ Before the Treatment } & \multicolumn{2}{|c|}{ At the end of 6 months } \\
\hline & Max PSD & Area PSD & Max PSD & Area PSD \\
\hline 1 & 0,00015 & 0,01137 & 0,00001 & 0,00109 \\
\hline 2 & 0,00009 & 0,00638 & 0,00001 & 0,00101 \\
\hline 3 & 0,00028 & 0,02380 & 0,00001 & 0,00076 \\
\hline 4 & 0,00031 & 0,02548 & 0,00002 & 0,00128 \\
\hline 5 & 0,00008 & 0,00492 & 0,00001 & 0,00072 \\
\hline 6 & 0,00033 & 0,02871 & 0,00001 & 0,00049 \\
\hline 7 & 0,00011 & 0,00956 & 0,00011 & 0,00811 \\
\hline 8 & 0,00015 & 0,01323 & 0,00009 & 0,00549 \\
\hline 9 & 0,00023 & 0,01278 & 0,00012 & 0,00668 \\
\hline 10 & 0,00048 & 0,02936 & 0,00005 & 0,00217 \\
\hline 11 & 0,00054 & 0,03590 & 0,00000 & 0,00006 \\
\hline 12 & 0,00026 & 0,02064 & 0,00001 & 0,00106 \\
\hline 13 & 0,00003 & 0,00250 & 0,00001 & 0,00047 \\
\hline 14 & 0,00032 & 0,01215 & 0,00004 & 0,00259 \\
\hline 15 & 0,00027 & 0,01883 & 0,00001 & 0,00062 \\
\hline Mean $\pm S E M$ & $0,00024 \pm 0,00004$ & $0,01704 \pm 0,00258$ & $0,00003 \pm 0,00001$ & $0,00217 \pm 0,00065$ \\
\hline
\end{tabular}

Table 1. Max PSD and Area PSD values calculated from EMG signals received right before placing the Twin Block appliance in the mouth over anterior temporal muscle and after 6 months treatment.

The mean values of Max PSD and Area PSD values, calculated from EMG signals for each patient, appear in the last lines of tables. The abbreviation SEM in the tables refers to "standard error of the mean."

\begin{tabular}{|c|c|c|c|c|}
\hline \multirow[t]{3}{*}{ Subject } & \multicolumn{4}{|c|}{ Massater } \\
\hline & \multicolumn{2}{|c|}{ Before the Treatment } & \multicolumn{2}{|c|}{ At the end of 6 months } \\
\hline & Max PSD & Area PSD & Max PSD & Area PSD \\
\hline 1 & 0,00012 & 0,01055 & 0,00017 & 0,01362 \\
\hline 2 & 0,00014 & 0,00997 & 0,00001 & 0,00018 \\
\hline 3 & 0,00011 & 0,01032 & 0,00001 & 0,00018 \\
\hline 4 & 0,00006 & 0,00593 & 0,00004 & 0,00327 \\
\hline 5 & 0,00007 & 0,00565 & 0,00015 & 0,01131 \\
\hline 6 & 0,00035 & 0,02834 & 0,00031 & 0,02579 \\
\hline 7 & 0,00011 & 0,01028 & 0,00073 & 0,06498 \\
\hline 8 & 0,00002 & 0,00148 & 0,00007 & 0,00557 \\
\hline 9 & 0,00083 & 0,05027 & 0,00037 & 0,02382 \\
\hline
\end{tabular}




\begin{tabular}{|c|c|c|c|c|}
\hline \multirow[t]{3}{*}{ Subject } & \multicolumn{4}{|c|}{ Massater } \\
\hline & \multicolumn{2}{|c|}{ Before the Treatment } & \multicolumn{2}{|c|}{ At the end of 6 months } \\
\hline & Max PSD & Area PSD & Max PSD & Area PSD \\
\hline 10 & 0,00012 & 0,00925 & 0,00001 & 0,00088 \\
\hline 11 & 0,00015 & 0,01340 & 0,00001 & 0,00035 \\
\hline 12 & 0,00016 & 0,01464 & 0,00012 & 0,00843 \\
\hline 13 & 0,00012 & 0,00945 & 0,00018 & 0,01456 \\
\hline 14 & 0,00032 & 0,02377 & 0,00003 & 0,00270 \\
\hline 15 & 0,00006 & 0,00497 & 0,00002 & 0,00046 \\
\hline Mean \pm SEM & $0,00018 \pm 0,00005$ & $0,01388 \pm 0,00315$ & $0,00015 \pm 0,00005$ & $0,01174 \pm 0,00438$ \\
\hline
\end{tabular}

Table 2. Max PSD and Area PSD values calculated from EMG signals received right before placing the Twin Block appliance in the mouth over masseter muscle and after 6 months treatment.

Before the treatment values (0. month) are greater for both the anterior temporal and masseter muscles, as seen in Table 1 and 2 . However, the difference between 0 . month and 6 months values more pronounced for anterior temporal. This difference is statistically significant for both features for anterior temporal but there was no significant difference for the masseter muscle (Table 3).

In addition, changes in the position with respect to base of the skull are significant (p: 0.001).

\begin{tabular}{|l|l|l|}
\cline { 2 - 3 } \multicolumn{1}{c|}{} & Max PSD & Area PSD \\
\hline Anterior Temporal & $\mathbf{0 . 0 0 0 1 4}$ & $\mathbf{0 . 0 0 0 1 2}$ \\
\hline Masseter & 0.5689 & 0.65591 \\
\hline
\end{tabular}

Table 3. p-values for "across treatment time" comparisons.

These observations are in-line with the results in the literature that "as a consequence of the use of functional appliances the length of the muscles around the jaw gets longer" (Du \& Hägg, 2003).

The PSD values of the EMG signals are depending on the power of the motor unit action potentials which makes up these EMG signals (Blinowska, 1979). Six-month-long treatment leads to a decrease in the amplitude and narrowing in the frequency range of motor unit action potentials and so PSD.

Looking at results obtained for anterior temporal muscle, it is seen that there is a significant difference between the onset of treatment and its values after 6 months for both attributes. This result is not valid for the masseter muscle. Albeit both muscles lie among jaw-closing muscles, the Twin-Block Appliance had a different impact.

It is known that the lower jaws of the people who have Class II malocclusion is placed behind their upper jaws. Twin Block appliances tries to keep lower jaw and upper jaw in the same position due to the fact that lower palate and upper palate have a contiguous structure. This can only be accomplished by forcing the lower jaw through forward. In this case, length of the jaw closing muscles must be changed so that the new position of the jaw becomes permanent. For that reason, it is a natural result for jaw closing muscles to clench 
with lower power density after 6 months. This result is matching the when the functional appliances is placed in the mouth, the jaw closing muscles become elongated ((Du \& Hägg, 2003; Miles et al., 1986; Woodside et al., 1983). Hence, the brawn of the jaw closing muscles reduces and the PSD values tend to decrease to lower amplitude.

However, this outcome was not realized for the masseter muscle. Therefore, it can be inferred that the effect of the Twin-Block Appliance on the masseter muscle did not come into existence in the first 6 months.

The critical objective of treatment by the Twin -Block appliance is to trigger the formation of an additional extension on jawbone. This objective can be achieved by increasing the development of cartilage belonging to condyle and also restricting the maxillary growth. The change also seen in the sizes of proximal muscles as a result of elongation of jawbone particularly reflected to EMG signals extracted for anterior temporal muscle. The reason why a similar difference did not form on the masseter muscle can be explained by that a position shift materialized on jawbone rather than an actual growth. Likewise, in studies carried out on Twin-Block treatment, it is seen that the question whether the observed change is an actual growth or a position shift has been debated. (Baccetti et. al. 2000; Trenouth, 2000). Additionally, it is observed that posterior teeth do not still contact one another when the appliance is removed at the end of 6 months in patients treated by the Twin-Block. This case brings about more intensive occlusion of anterior teeth of patients and further contraction on front fibers of the masseter muscle. This impact hinders the occurrence of adaptation coming into being in masseter muscles in EMG recordings received during jaw closing/ constriction.

The patient must be observed in a longer period in order to follow the consequences which will be resulted from this condition.

\section{Conclusion}

The use of EMG signals in studies related to face muscles continues with an increasing interest. Muscle structure responsible for masticatory function and soft tissue belonging to face does not only affect bone development but also affects the period of orthodontic treatments and permanency of success achieved after treatment. EMG is a primary instrument to record this functional process and for the effect of skull traction. For these reasons, analysis of noninvasive EMG by appropriate methods can provide further information regarding the effect of treatment and service lives of appliances (Eckardt et al. 1997).

In the literature, there are some EMG studies that they are based one removable appliances. However, these kinds of appliances are worn only during night time (Tallgren et al. 1998; Ahlgren , 1960). Hence, the appliances act as a splint rather than an activator. On the other hand, the functional appliances that are worn full-time like the Twin-Block stimulate greater than those worn only part-time. For that reason, this study which is about the EMG and the Twin-Block, is important in order to investigate the muscle response.

The PSD is the feature regularly used for frequency domain analysis of EMG. An integration of the PSD over all frequencies yields the entire power. PSD value was chosen as a feature in order to evaluate the effects of the appliances. That's because PSD value is a parameter which is frequently used in the evaluation of the EMG signals and it gives information on power of total action potential formed by the muscles during tightening.

EMG and PSD are quite successful in showing the change occurred in the muscles. However, criteria must be determined for different age groups in using different trainers. 
Moreover, if an expert system, which evaluates the functionality of the orthodontic appliances for the orthodontists; which estimates the treatment period; and which enables a follow-up for the effect of the applied orthodontic appliances on the person, is desired to be developed with artificial intelligence applications, PSD attribution will be insufficient for the input value. For that reason, orthodontists and engineers must enable different parameters to become evaluable by continuing their interdisciplinary studies.

\section{Acknowledgment}

The authors are grateful for the grant support provided by The Scientific \& Technological Research Council of Turkey - TÜBİTAK, contract number 106E144.

\section{References}

Rangayyan R. M., (2002). Introduction to Biomedical Signals, In: Biomedical Signal Analysis: A Case-Study Approach, Akay, M., (Ed),. pp. 1-14, Wiley-IEEE Press, ISBN 0-471-208116, New York

Reaz, M. B. I., Hussain M. S., Mohd-Yasin F., (2006). Techniques of EMG signal analysis: detection, processing, classification and applications. Biological Procedures Online Vol.8, No. 1, pp. $11-35$.

Moritani, T., Stegeman, D., Merletti R., (2004). Basic physiology and biophysics of EMG signal generation. In: Electromyography: Physiology, Engineering, and Non-Invasive Applications, Merletti, R., Parker, P. (Eds), pp. 1 - 26, Wiley-IEEE Pres,

Cobbold, R. S. C., Transducers for Biomedical Measurements: Principles and Applications, John Wiley \& Sons, Inc., New York, (1974).

Kraus F., (1956) Vestibular and oral screens. Trans Eur Orthod Soc.; 32: 217-224

Kleissen R.F., Buurke J.H., Harlaar J., Zilvold G., Electromyography in the biomechanical analysis of human movement and it clinical application, Gait Posture, 8, 143-158, (1998).

Riedel R. A., The relation of maxillary structures to cranium in malocclusion and normal occlusion. Angle Orthod;22:142-145, (1952).

McNamara J. A. Components of Class II malocclusion in children 8-10 years of age. Angle Orthod.; 51:177-202 (1981).

Renfroe EW. A study of the facial patterns associated with Class I, Class II division 1 and Class II, division 2 malocclusions Angle Orthod;19:12-15, (1948).

Blair E.S. A cephalometric roentgenographic appraisal of the skeletal morphology of Class I, Class II, division 1 and Class II, division 2 malocclusion. Angle Orthod.;24:106-119, (1954).

Proffit W. R., Fields H. W., Moray L. J., Prevelance of malocclusion and orthodontic treatment need in the United States: estimates from the N-HANES III survey Int. J. Adult Orthod. Orthog. Surg.;13:97-106 (1998).

McNamara JA Jr. Brudon WL. Orthodontics and dentofacial orthopedics. Ann Arbor: Needham Pres;:67-80 (2001).

Hunter W. S., The vertical dimensions of the face and skeletodental retrognatizm. Am J Orthod; 53:586-595, (1967).

Rogers A. Concepts of functional jaw orthopedics. In: Graber TM, Neumann B, editors. Removable orthodontic appliances. 2nd ed. Philadelphia: Saunders;. p. 87. (1984). 
Basciftci F. A., Uysal T, Büyükerkmen A, Sarı Z. (2003) “The effects of activator treatment on the craniofacial structure of Class II division 1 patients". Eur J Orthod.;25:87-93.

Clark WJ. Twin block functional theraphy applications in dentofacial orthopedics. 2nd ed. Mosby-Wolfe Press, St Louis (2002).

Jena AK, Duggal R, Parkashc H. Skeletal and dentoalveolar effects of Twinblock and bionator appliances in the treatment of Class II malocclusion: A comparative study. Am. J. Orthod. Dentofacial Orthop. 130:594-602, (2006).

Harvold EP. Bone remodelling and orthodontics. Eur J Orthod;7:217-230, (1985).

Pancherz H. The mechanism of Class II correction in Herbst appliance treatment. A cephalometric investigation. Am J Orthod;82:104-113, (1982).

Birkeback L, Melsen B, Terp S. A laminographic study of the alterations in the temporomandibular joint following activator treatment Eur J Orthod;6:267-276, (1984).

Lund D. L., Sandler P.J., The effects of Twin Blocks: a prospective controlled study. Am J Orthod Dentofacial Orthop;113: 104-10, (1998).

Mills C, McCulloch K. Treatment effects of the Twin-block appliance: a cephalometric study. Am J Orthod 1998;114:15-24.

Toth LR, McNamara JA, Jr. Skeletal and dentoalveolar adaptations produced by Twin-block appliance treatment. AmJ Orthod Dentofacial Orthop 1999;116:597-609.

Clark WJ. The Twin-block traction technique. Eur J Orthod 1982;4:129-38.

Clark WJ. The Twin-block technique. Am J Orthod Dentofacial Orthop 1988;93:1-18.

Graber TM, Rakosi T, Petrovic AG. "Dentofacial orthopedics with functional appliances". St Louis: CV Mosby; 1985.

Graber TM. Physiologic principles of functional appliances. St Louis: CV Mosby; 1985

Woodside DG, Altuna G, Harvold E, Herbert M, Metaxas A. Primate experiments in malocclusion and bone induction. Am J Orthod 1983;83:460-8.

McNamara Jr JA. Neuromuscular and skeletal adaptations to altered function in the orofacial region. Am J Orthod 1973;64:578-606.

Pancherz H. A Cephalometric analysis of skeletal and dental changes contributing to Class II correction in activator treatment. Am J Orthod 1984;85:125-34.

Pancherz H., The nature of Class II relapse after Herbst appliance treatment: a cephalometric long-term investigation. Am J Orthod Dentofacial Orthop;100:220-33, (1991).

Mcnamara JA Jr. Rolf Fränkel, 1908-2001 (in memoriam). Am. J. Orthod. Dentofacial Orthop.;121:238-9 (2002).

Pancherz H, Fackel U. The skeletofacial growth pattern pre- and post-dentofacial orthopaedics. A long-term study of Class II malocclusions treated with the Herbst appliance. Eur J Orthod;12:209-18, (1990).

Vogt W. A new fixed interarch device for Class II correction, J. Clin. Orthod. 2003;37:36-41

Awbrey J.J. The Bite-Fixer, Clinical Impressions, Ormco/A Company. 1999;8:10-16.

Pancherz H. The Herbst appliance. Its biologic effects and clinical use, Am. J. Orthod. 1985;87:1-20

Pancherz H., Malmgren O, Ha"gg U, Omblus J, Hansen K. Class II correction in Herbst and Bass therapy. Eur J Orthod;11:17-30, (1989).

Proffit WR, Fields HW, editors. Contemporary orthodontics. 3rd ed. St Louis: Mosby; (2000).

Duchêne J. and Gouble F. Surface electromyogram during voluntary contraction: Processing tools and relation to physiological events. Critical Reviews in Biomedical Engineering 21(4): 313-397, (1993). 
Pozzo M., Farina D., Merletti R., Electromyography:Detection, Processing and Applications Biomedical Technology and Devices Handbook, CRC press, 2004.

Panagiotacopulos N. D., J. S. Lee, M. H. Pope, K. Friesen, (1998) Evaluation of EMG signals from rehabilitated patients with low back pain using wavelets. J. of Electromyog. and Kinesiology, vol. 8, pp. $269-278$,

Kim, R. B. Hanson, T. L. Abell, and J. R. Malagelada. (1989) Effect of inhibition of prostaglandin synthesis on epinephrine-induced gastroduodenal electromechanical changes in humans. Mayo Clinic Proc. 64:149-157,.

Farina D., R. Merletti, D. F. Stegeman, (2004) Biophysics of the generation of EMG signals. In: Electromyography: Physiology, Engineering, and Non-Invasive Applications, New York, Wiley-IEEE Pres. , pp. 81 - 107.

Kay, S.M. , and Marple, S.L., (1981) Spectrum Analysis-A Modern Perspective, Proceedings of IEEE Transactions 69(11):1380-1419.

Kay S.M., Modern Spectral Estimation: Theory and Application. Prentice Hall-Englewood Cliffs, NJ, (1988).

Okeson J. P.,: “Management of Temporomandibular disorders and occlusion”, Mosby, St. Louis Fourth edition (1998), pp:160-162.

Blinowska, A., Verroust, J., Cannet, G., "The Determination of motor unit characteristics from the low frequency electromyographic power spectra". Electromyography and Clinical Neurophysiology, 19, 281 - 290, (1979).

Kwatny, E., Thomas, D., Kwatng, H., (1970). An application of signal processing techniques to the study of myoelectric signals. IEEE Transactions on Biomedical Engineering $17,303-312$.

Marple S.L., Digital Spectral Analysis with Applications. Prentice Hall-Englewood Cliffs, NJ, 1987.

Kaluzynski K., Order Selection in Doppler Blood Flow Signal Spectral Analysis Using Autoregressive Modelling, Medical \& Biological Engineering \& Computing, 27, 8992, (1989).

Du X., Hägg U. "Muscular adaptation to gradual advancement of the mandible". Angle Orthod., vol. 73, pp. 525 - 531, (2003).

Miles T. S., Nordstrom M. A., Turker K. S., "Length - related changes in activation threshold and waveform of motor units in human massater muscle", Journal of Physiology (London) vol. 370, pp. 457 - 465, (1986).

Baccetti T. et al. Treatment timing for Twin-block therapy. Am J Orthod dentofacial Orhop 2000;118:159-70.

Trenouth M. Cephalometric evaluation of the Twin block appliance in the treatment of Class II Division 1 malocclusion with matched normative growth data. Am J Orthod Dentofacial Orthop 2000;117:54-59.

Eckardt, L., Harzer, W., Schneevoigt, R., 1997. Comparative study of excitation patterns in the masseter muscle before and after orthognathic surgery. Journal of CranioMaxillojacial Surgery 25, 344-352

Tallgren, A., Christiansen, R., Ash, M. M., Miller, R. L., (1998) Effects of a myofunctional appliance on orofacial muscle activity and structures. Angle Orthodontists. 3, 249258.

Ahlgren J., (1960) An Electromyographic analysis of the response to activator therapy. Odontol Revy 11, 125. 


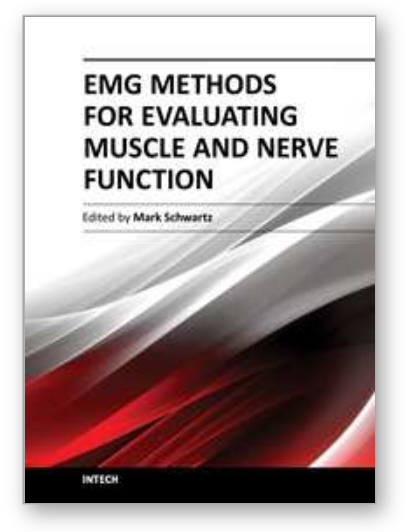

\author{
EMG Methods for Evaluating Muscle and Nerve Function \\ Edited by Mr. Mark Schwartz
}

ISBN 978-953-307-793-2

Hard cover, 532 pages

Publisher InTech

Published online 11, January, 2012

Published in print edition January, 2012

This first of two volumes on EMG (Electromyography) covers a wide range of subjects, from Principles and Methods, Signal Processing, Diagnostics, Evoked Potentials, to EMG in combination with other technologies and New Frontiers in Research and Technology. The authors vary in their approach to their subjects, from reviews of the field, to experimental studies with exciting new findings. The authors review the literature related to the use of surface electromyography (SEMG) parameters for measuring muscle function and fatigue to the limitations of different analysis and processing techniques. The final section on new frontiers in research and technology describes new applications where electromyography is employed as a means for humans to control electromechanical systems, water surface electromyography, scanning electromyography, EMG measures in orthodontic appliances, and in the ophthalmological field. These original approaches to the use of EMG measurement provide a bridge to the second volume on clinical applications of EMG.

\title{
How to reference
}

In order to correctly reference this scholarly work, feel free to copy and paste the following:

Şükrü Okkesim, Tancan Uysal, Asıı Baysal and Sadık Kara (2012). EMG PSD Measures in Orthodontic Appliances, EMG Methods for Evaluating Muscle and Nerve Function, Mr. Mark Schwartz (Ed.), ISBN: 978953-307-793-2, InTech, Available from: http://www.intechopen.com/books/emg-methods-for-evaluatingmuscle-and-nerve-function/emg-psd-measures-in-orthodontic-appliances

\section{INTECH}

open science | open minds

\section{InTech Europe}

University Campus STeP Ri

Slavka Krautzeka 83/A

51000 Rijeka, Croatia

Phone: +385 (51) 770447

Fax: +385 (51) 686166

www.intechopen.com

\section{InTech China}

Unit 405, Office Block, Hotel Equatorial Shanghai

No.65, Yan An Road (West), Shanghai, 200040, China

中国上海市延安西路65号上海国际贵都大饭店办公楼 405 单元

Phone: +86-21-62489820

Fax: $+86-21-62489821$ 
(C) 2012 The Author(s). Licensee IntechOpen. This is an open access article distributed under the terms of the Creative Commons Attribution 3.0 License, which permits unrestricted use, distribution, and reproduction in any medium, provided the original work is properly cited. 